\title{
Differential regulatory effect of progesterone on the proliferation and apoptosis of uterine leiomyoma tissue explants and primary leiomyoma cell cultures
}

\author{
Dmitry Voronin ${ }^{1}$, Natalia Sotnikova ${ }^{1}$, Kirill Rukavishnikov ${ }^{1}$, Anna Malyshkina ${ }^{1}$, Sergey Nagornii ${ }^{1}$, Yulia Antsiferova ${ }^{1}$ \\ ${ }^{1}$ Federal state budget establishment "Ivanovo's Research Institute of Maternity and Childhood named V.N. \\ Gorodkov" of the Health Ministry of Russian Federation, Ivanovi, Russia
}

\begin{abstract}
Objective: The growth of uterine leiomyomas is regulated by progesterone, although the underlying molecular mechanisms are not fully understood.

Methods: Primary leiomyoma cells were isolated by standard method from 16 samples of uterine leiomyoma tissue. Uterine leiomyoma explants and primary leiomyoma cell cultures were exposed to progesterone in concentrations of $0.01 \mu \mathrm{g} / \mathrm{ml}, 0.1 \mu \mathrm{g} / \mathrm{ml}$ and $1 \mu \mathrm{g} /$ $\mathrm{ml}$ for $24 \mathrm{~h}$. Cell apoptosis was assessed with Annexin $\mathrm{V}$ assays performed in cell cultures by flow cytometry. The expression of PR-A, PR-B, Ki67, Akt, ERK, PTEN and PPARY mRNAs was estimated in cultured leiomyoma cells and tissue explants by real time RT-PCR.

Results: Treatment with progesterone promoted viability and proliferation of cultured leiomyoma cells in a dose-dependent manner. Low and high doses of progesterone decreased early apoptosis of leiomyoma cells. High concentrations of progesterone increased the number of living cells in Annexin $V$ assays. High doses of progesterone increased the expression of $\mathrm{Ki} 67$ mRNA, while low doses increased the expression of PR-A mRNA in cultured leiomyoma cells and tissue explants. In cell cultures, low doses of progesterone increased the expression of PR-B mRNA and the expression of PTEN and PPARY mRNAs in a dose-dependent manner. Exposure of leiomyoma tissue explants to progesterone led to increased expression of PR-B and ERK mRNAs in a dose-dependent manner.

Conclusions: The effects of progesterone on the apoptosis and proliferation of leiomyoma cells was dosedependent and different in cell cultures and leiomyoma explants, possibly as a result of impacts derived from the tumor microenvironment.
\end{abstract}

Keywords: leiomyoma, progesterone, cell cultures, proliferation, apoptosis

\section{INTRODUCTION}

Uterine leiomyoma (or fibroid) is a benign myometrial smooth muscle cell tumor, which consists of transformed smooth muscle cells, connective tissue fibroblasts, and a large amount of extracellular matrix (Chegini, 2010). Leiomyoma is the most common tumor of the female genital tract with an incidence of $40-70 \%$ in women of reproductive age (Commandeur et al., 2015). This tumor has been associated with severe clinical symptoms such as excessive uterine bleeding, pelvic pain and pressure, dysmenorrhea, sexual dysfunction, infertility, recurrent pregnancy loss, and compression of adjacent pelvic organs by large uterine fibroids (Commandeur et al., 2015). There is no effective medical treatment for uterine leiomyomas, with surgery standing as the treatment of choice (Havryliuk et al., 2017). However, hysterectomy carries an increased risk of postoperative complications and leads to partial or complete loss of reproductive function, a most undesired outcome for young women in particular. Therefore, searching for drug candidates to regulate uterine leiomyoma growth is of great importance for the development of effective therapies for leiomyomas.

Estrogen and progesterone are believed to regulate leiomyoma growth (Reis et al., 2016). The development of uterine leiomyomas during one's active reproductive age and the significant decrease in the number of cases following menopause support this proposition (Reis et al., 2016). Estrogen had been considered as the main hormone involved in leiomyoma development (Kasai et al., 2004). However, recent studies showed that progesterone also plays an important role in leiomyoma growth (Kim et al., 2009). The expression of progesterone receptors (PR) is significantly increased in uterine leiomyoma tissue when compared to the adjacent normal myometrium (Kim et al., 2009). Acting via PR, progesterone interacts with the $\mathrm{Bcl}-2$ promoter to induce the expression of $\mathrm{Bcl}-2$ expression in leiomyoma tissue, thus suppressing the apoptosis of tumor cells (Yin et al., 2007). The addition of progesterone to uterine leiomyoma cell cultures resulted in increased proliferation and cell nuclear antigen (PCNA) expression (Maruo et al., 2000). Using an experimental leiomyoma xenograft model, Ishikawa et al. (2010) demonstrated that progesterone and its receptors directly stimulated tumor growth, while estrogen and its receptor only sustained PR expression in leiomyoma tissue. The stimulatory effects of progesterone in leiomyoma cell proliferation and growth have been clearly demonstrated, but the molecular mechanisms underlying this phenomenon have not been fully investigated.

Progesterone was shown to activate several intracellular signaling pathways, which effects are mediated by progesterone receptors (Lange, 2008). Ligand-activated PRs can activate the MAPK/ERK signaling pathway (Hennessy et al., 2005). Increased MAPK activity may strongly increase the survival and proliferation of tumor cells in general and breast cancer cells in particular (Lange, 2008). Progesterone may also act via the PI3K/Akt pathway, which controls cells proliferation, survival, differentiation and apoptosis (Kim et al., 2009). Hyperactivation of the PI3K/Akt pathway is common in breast, endometrial, prostate, lung, and ovarian cancer (Hennessy et al., 2005). Recently, it was shown that progesterone may rapidly phosphorylate Akt in leiomyoma cells (Hoekstra et al., 2009), with higher levels of Akt and the phosphorylated form of Akt reportedly occurring in uterine leiomyoma cells that in the myometrium (Kim et al., 2009). A known important negative regulator of Akt, tumor suppressor PTEN (phosphatase and tensin homolog), a non-redundant, evolutionarily conserved phosphatase, affects cell cycle progression, proliferation, chemotaxis and apoptosis (Keniry \& Parsons, 2008). Expression of PTEN mRNA and protein levels was increased in uterine leiomyomas when com- 
pared to normal myometrium (Makker et al., 2016). Recent reports indicated that transcription factor PPARY (peroxisome proliferator-activated receptor $y$ ) transcriptionally up-regulates PTEN expression in tumor cells, with higher levels of expression of PPARY mRNA seen in uterine leiomyomas when compared to adjacent normal myometrial tissue (Jeong et al., 2010). The relationship between PTEN, PPARY expression and progesterone action in uterine leiomyomas is still unclear.

Several hormone therapies have been proposed to treat uterine leiomyomas, including gonadotropin-releasing hormone (GnRH) agonists, selective estrogen receptor modulators (SERMs), and selective progesterone receptor modulators (SPRMs). All such therapies were designed to abolish steroid action, suppress leiomyoma growth, and diminish symptom severity (Chegini, 2010). However, these agents often provide limited clinical effect on the size of uterine leiomyomas. Significant side effects such as hot flashes and bone loss (Commandeur et al., 2015) have been described. The limitations associated with medical treatment have been driven mostly by lack of complete information on how hormone therapies work at a molecular level. Almost every effect of progesterone has been studied using leiomyoma cell cultures, although the data gathered on the cell- and tissue-specific effects of ovarian steroids is rather compelling (Chegini, 2010). Special interest resides in comparing the impact of progesterone on leiomyoma tissue and leiomyoma cell cultures, describing the impact the tumor microenvironment may have on how progesterone regulates leiomyoma growth, and clarifying the relevance of cell culture models in the elucidation of the mechanisms by which progesterone operates in in vivo conditions.

The following were investigated in this study: i) the dose-dependent action of progesterone on the apoptosis and growth of leiomyoma cells; ii) the dose-dependent and tissue-specific action of progesterone on leiomyoma cell proliferative activity and expression of progesterone receptors PR-A and PR-B; iii) the dose-dependent tissue-specific action of progesterone on the activation of MAPK/ERK and Akt signaling pathways and on the expression of PTEN and PPARY to compare the effects of the hormone in cell cultures and whole tissue.

\section{MATERIALS AND METHODS}

Tissue collection and sample preparation

Samples of uterine leiomyoma tissue were collected from 16 women undergoing myomectomy for symptomatic uterine leiomyoma at the Gynecological Clinic of the Ivanovo State Research Institute of Maternity and Childhood (Ivanovo, Russia). Patients had been off hormone treatment for at least three months prior to surgery. The women included in the study were of reproductive age (32-42 years). All samples were collected in the proliferative phase of the cycle from relatively large myomas $(6.23 \pm 0.63 \mathrm{~cm}$ in diameter) of intramural localization. The collected samples did not have signs of hemorrhage or necrosis. The local Ethics Committee of the State Research Institute of Maternity and Childhood (Ivanovo, Russia) approved the use of these tissue samples. The patients gave written consent before joining the study.

The samples were collected from the peripheral areas of the uterine leiomyomas, since these areas exhibited robust growth (Mas et al., 2015). Fresh leiomyoma tissue samples were rinsed in RPMI 1640 culture medium with $1 \%$ antibiotic solution, containing penicillin $100 \mathrm{IU} / \mathrm{ml}$ and streptomycin $100 \mathrm{mg} / \mathrm{ml}$; after washing, the samples were sliced manually into small pieces measuring approximately 2-3 $\mathrm{mm}^{3}$. Each sample was divided into two parts: one used as a tissue explant in the experiments with progesterone; and the other was digested using an enzyme solution to receive the primary leiomyoma cell culture.

\section{Primary cell isolation and cell culture}

Primary leiomyoma cells were isolated as described in the literature (Koohestani et al., 2013). In summary, minced leiomyoma tissue samples were digested by incubation in DMEM solution (Sigma Aldrich) containing Collagenase (Sigma Aldrich) $0.1 \mathrm{mg} / \mathrm{m}$ and DNAse IV 0.05 $\mathrm{mg} / \mathrm{ml}$ (Sigma Aldrich) for $1-2 \mathrm{~h}$ at $37^{\circ} \mathrm{C}$ and $5 \% \mathrm{CO}_{2}$ with constant agitation. Ten milliliters of DMEM solution with enzymes was used to digest $1 \mathrm{~g}$ of leiomyoma tissue. Then the cells were incubated overnight in the same enzyme solution without agitation, and were subsequently incubated for $10 \mathrm{~min}$ under constant agitation after the addition of trypsin to a final concentration of $10 \mu \mathrm{g} / \mathrm{ml}$. Cell suspensions were filtered to remove undigested tissues. The cells were resuspended in DMEM solution containing $1 \%$ antibiotic mixture and $10 \%$ heat-inactivated fetal calf serum; $1 \times 10^{6}$ cells were seeded in 24 -well cultures plates and incubated overnight. Then, non-adherent cells were removed by washing with phosphate buffer solution (PBS) and the cell cultures were continued after the addition of fresh DMEM medium.

\section{Progesterone treatment}

To estimate the cell- and tissue-specific effects of progesterone on the proliferation and apoptosis of uterine leiomyomas, leiomyoma explants and primary leiomyoma cell cultures were exposed to progesterone (Sigma) at concentrations of $0.01 \mu \mathrm{g} / \mathrm{ml}, 0.1 \mu \mathrm{g} / \mathrm{ml}$, and $1 \mu \mathrm{g} / \mathrm{ml}$ for 24 h. Control tissue explants and cell cultures were cultivated in DMEM solution alone. After incubation, tissue explants and culture cells were fixed for RNA isolation and RT-PCR testing. Additionally apoptosis of progesterone-stimulated primary culture cells was estimated by flow cytometry. To estimate the prolonged effect of progesterone on leiomyoma cells, primary cell cultures, after exposure to progesterone, were kept in fresh DMEM medium without progesterone for $72 \mathrm{~h}$; the estimation of cell viability and morphology in the cultivation process was performed using a light microscope. Morphology analysis was performed in an Axiovert 200 inverted transmitted light microscope at 50x magnification (Carl Zeiss, Germany). Images were captured using an AxioCam digital camera from Zeiss.

\section{Flow cytometry for apoptosis detection}

The phenotype and apoptosis of leiomyoma culture cells were studied by flow cytometry. To this end, uterine leiomyoma primary culture cells exposed to progesterone for 24 hours were gently detached with a cell scraper, pipetted into single cells, and suspended at $1 \times 10^{6} / \mathrm{ml}$. The cells were washed twice with PBS, stained with desmin (a smooth muscle cell differentiation marker), and analyzed for apoptosis. Intracellular staining with anti-desmin monoclonal antibodies (eBioscience ${ }^{\mathrm{TM}}$, USA) was performed. Before antibody staining, a cell membrane fixation and permeabilization procedure was performed using Fixative Solution IOTest ${ }^{\circledR 3}$ 10x Concentrate kit (Beckman Coulter, USA). Apoptosis of leiomyoma cells was measured using an Annexin V-FITC apoptosis detection kit (Invitrogen, USA) according to the manufacturer's protocol. Annexin V/Propidium iodide (PI) double staining made it possible to distinguish between viable (Annexin V-PI-), early apoptotic (Annexin V+PI-), late apoptotic (Annexin $\mathrm{V}+\mathrm{PI}+$ ), and dead cells (Annexin V-PI+). The analysis was performed in a BD FACSCanto II flow cytometer (Becton Dickinson, USA). At least 50,000 cells were counted in each analyzed sample. Mouse IgG (IgG1-FITC + IgG2a-PE) antibodies (Becton Dickinson, San Hose, CA, USA) were 
used to estimate unspecific cell staining. The criteria for positive staining were set at a fluorescent intensity displayed by $<0.5 \%$ of the cells stained with the appropriate fluorochrome-conjugated isotype control monoclonal antibodies (mAb). Data were analyzed using the Diva software (Becton Dickinson, USA). Gating strategies are shown in the figure legends.

\section{Real-time PCR}

Quantitative real-time PCR was performed to examine Ki67, PR-A and PR-B, ERK, Akt, PTEN, PPARy, mRNAs expression in leiomyoma tissue explants and primary culture cells after incubation with progesterone. Total RNA was extracted from samples using the standard acid guanidinium thiocyanate-phenol-chloroform method. The amount of RNA in each sample was estimated with a Nano Drop 2000C (Thermo Scientific, USA) spectrophotometer. Five micrograms of RNA was reverse-transcribed into cDNA using a commercial kit (Fractal Bio, St. Petersburg, Russia), according to the manufacturer's protocol. Real-time PCR was performed with iCycler IQ software (BIO-RAD, CA, USA). Commercial kits for quantitative estimation of specific gene mRNAs expression (Fractal Bio, St. Petersburg, Russia) were used. Quantification was performed for the expression of $\beta$-actin, a compound expressed consistently in uterine leiomyoma tissue and leiomyoma cells used as housekeeping gene. A series of control DNA dilutions were used to generate standard curves and the number of copies of cDNA of specific genes was defined and normalized to $\beta$-actin expression. Results for mRNAs expression of the studied genes are presented as a normalized number of copies $\times 10^{3}$ per $\mu$ l.

\section{Statistical analysis}

Data were treated using the STATISTICA 6.0 software program. The results were presented as mean \pm standard error for variables with a normal distribution, and as median, first quartiles, third quartiles for variables with non-normal distributions. Initial statistical analysis was made using ANOVA. Statistical analysis was performed with the Bonferroni correction on two-tailed Student's t-test for variables with a normal distribution and the Mann-Whitney $U$-test for variables following a non-normal distribution. $P$ values $<0.05$ were considered significant.

\section{RESULTS}

Morphology of the uterine leiomyoma cell cultures after treatment with different concentrations of progesterone

After 72 hours of incubation, control leiomyoma cells had comparatively small round shapes with oval nuclei (Fig. 1a). The cells treated with progesterone $0.01 \mu \mathrm{g} / \mathrm{ml}$ and $0.1 \mu \mathrm{g} / \mathrm{ml}$ were more elongated and had intact cigar shaped nuclei (Fig. 1b and 1c). The number of leiomyoma cells treated with progesterone $0.1 \mu \mathrm{g} / \mathrm{ml}$ grew by $40 \%$ and some cellular crowding, suggestive of proliferation, was observed (Fig. 1c) $(p=0.025)$. The cells treated with progesterone $1 \mu \mathrm{g} / \mathrm{ml}$ increased 3 -fold $(p=0.011)$. These cells appeared to be robust, were spindle-shaped and had elongated nuclei; they showed maximal cellular crowding and proliferation (Fig. 1d).

Effect of different concentrations of progesterone on leiomyoma cell apoptosis

Annexin V-FITC/PI assays were performed to investigate whether the stimulatory effect of progesterone on the proliferation of leiomyoma cell cultures was attributed to the apoptotic mechanism. The analyzed leiomyoma cells had predominantly the phenotype of muscle cells, which was confirmed by staining with desmin (Fig. 2c).
Approximately $70-80 \%$ of the analyzed cells were positive for intracellular desmin expression. A statistically significant decrease was observed in the number of early apoptotic Annexin V+PI- cells in cultures after treatment with progesterone $0.01 \mu \mathrm{g} / \mathrm{ml}$ and $1 \mu \mathrm{g} / \mathrm{ml}$ (Fig. 2e). High doses of progesterone $(1 \mu \mathrm{g} / \mathrm{ml})$ significantly increased the number of living Annexin V-PI- cells (Fig. 2e). The number of late apoptotic and dead cells remained unchanged after incubation with progesterone.

Effect of different concentrations of progesterone on Ki67, PR-A and PR-B mRNAs expression by uterine leiomyoma explants and primary leiomyoma cells

We studied proliferation marker Ki67 mRNA expression in leiomyoma explants and primary leiomyoma cells after treatment with different concentrations of progesterone for $24 \mathrm{~h}$ to confirm the stimulatory action of progesterone. We found that high doses of progesterone $(1 \mu \mathrm{g} / \mathrm{ml})$ significantly increased Ki67 mRNA expression both in tissue explants and cell cultures (Fig. 3a). It is well known that progesterone action in the uterus is mediated through specific nuclear progesterone receptors - PR-A and PR-B isoforms (Kim at al., 2009). We found that in leiomyoma tissue explants the expression of PR-A mRNA significantly increased after the explants were treated with progesterone at a low concentration $(0.01 \mu \mathrm{g} / \mathrm{ml})$ (Fig. 3b). PR-B mRNA expression in tissue explants was elevated after tissue exposure to progesterone at concentrations of $0.1 \mu \mathrm{g} / \mathrm{ml}$ and $1 \mu \mathrm{g} /$ $\mathrm{ml}$ (Fig. 3c). Leiomyoma cell cultures showed increased PR-A and PR-B mRNAs expression after treatment with progesterone $0.01 \mu \mathrm{g} / \mathrm{ml}$ (Fig.3b, 3c). PR-A mRNA expression was greater in myoma explants than cell cultures after treatment with progesterone $0.1 \mu \mathrm{g} / \mathrm{ml}$ and $1 \mu \mathrm{g} / \mathrm{ml}$ (Fig. 3b).

Effect of different concentrations of progesterone on ERK, AKT, PTEN and PPARY mRNAs expression in uterine leiomyoma explants and leiomyoma cells

To estimate the stimulatory action of progesterone on leiomyoma cells cultures and leiomyoma tissue, we looked into the effects of progesterone on the activation of two intracellular pathways associated with cell activation and proliferation, MAPR/ERK and Akt (Fig. 4). We found that progesterone $0.01 \mu \mathrm{g} / \mathrm{ml}$ and $1 \mu \mathrm{g} / \mathrm{ml}$ significantly increased ERK mRNA expression in uterine leiomyoma tissue explants (Fig. 4a). Progesterone did not affect ERK and Akt mRNAs expression in uterine leiomyoma cell cultures. It must be noted, however, that uterine leiomyoma cell cultures expressed Akt mRNA more intensively than tissue explants. Significantly higher expression of Akt mRNA was noted in cell cultures incubated with DMEM medium only (control) and with progesterone $1 \mu \mathrm{g} / \mathrm{ml}$ (Fig. 4b). Differently from tissue explants, leiomyoma cell cultures showed decreases in PTEN and PPARY mRNAs expression after incubation with progesterone $0.1 \mu \mathrm{g} / \mathrm{ml}$ and $1 \mu \mathrm{g} / \mathrm{ml}$ (Fig. 4c, d). The level of PPARy mRNA expression by control leiomyoma cells was significantly higher than that of tissue explants (Fig. 4d).

\section{DISCUSSION}

Our results have demonstrated the stimulatory effect of progesterone on uterine leiomyoma cell growth. We found that progesterone acts on primary cultures of uterine leiomyoma cells in a dose-dependent manner, increasing the proliferation and inhibiting the apoptosis of leiomyoma cells. Increased Ki67 mRNA expression and greater number of living cells in Annexin $V$ tests after exposure of leiomyoma cells to progesterone confirmed this statement. Our results presented good agreement with the literature, demonstrating the growth-promoting action of 
a)

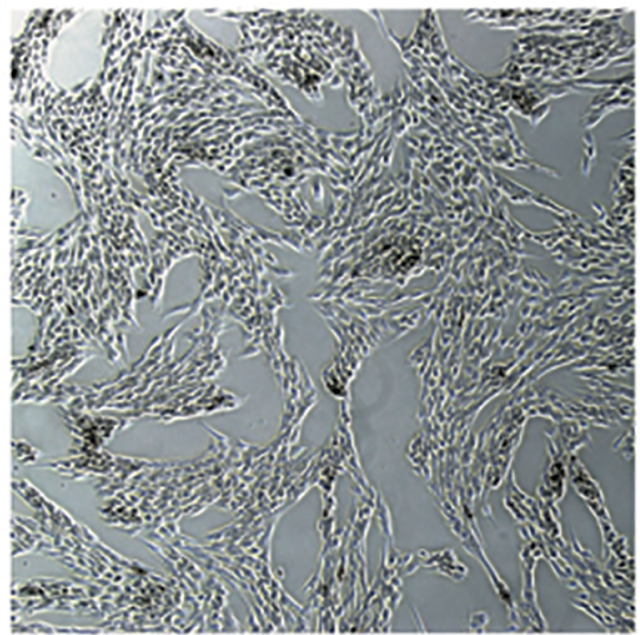

c)

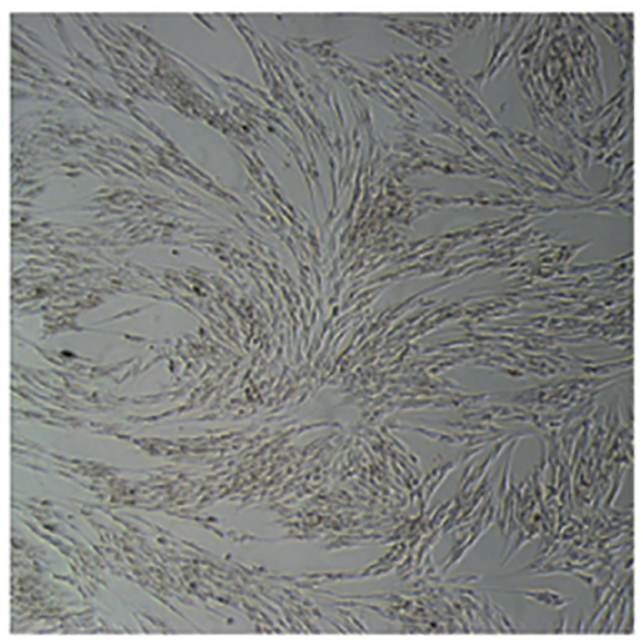

b)

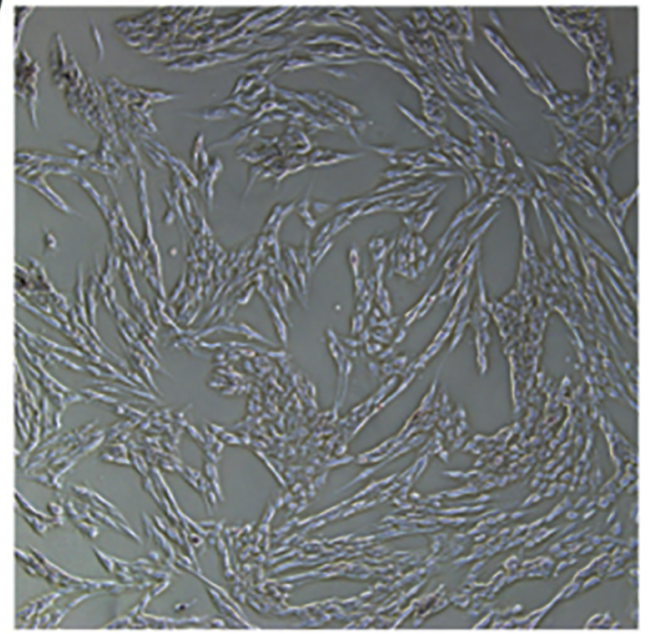

d)

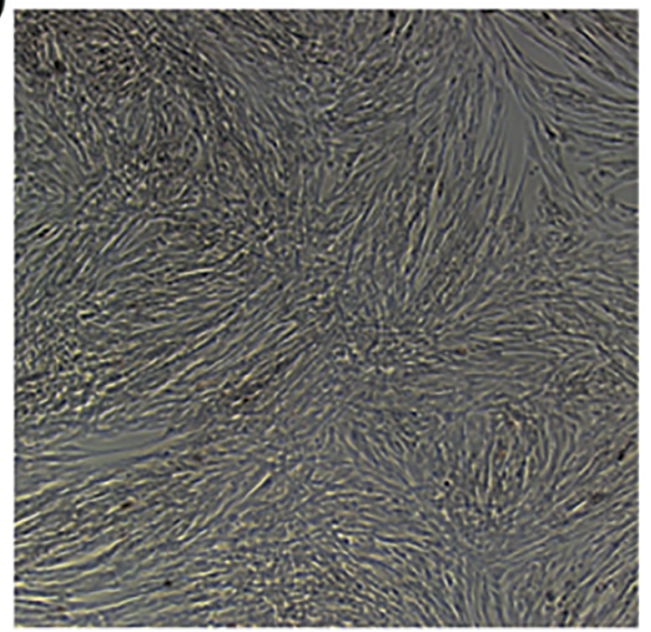

Figure 1. Primary cultures of leiomyoma cells after incubation with different concentrations of progesterone Photographs showing the effect of progesterone $0.01 \mu \mathrm{g} / \mathrm{ml}(\mathrm{b}), 0.1 \mu \mathrm{g} / \mathrm{ml}$ (c) and $1 \mu \mathrm{g} / \mathrm{ml}(\mathrm{d})$ on leiomyoma cell cultures after $72 \mathrm{~h}$ of treatment. Cells incubated only in culture medium were used as controls (a). Photographs were taken with a phase-contrast microscope (50x magnification).

progesterone on leiomyoma cells (Reis et al., 2016; Kim et al., 2009). The stimulatory action of progesterone on leiomyoma cells in vitro is mediated via the elevation of activity of anti-apoptotic factor $\mathrm{Bcl}-2$ (Yin et al., 2007; Maruo et al., 2000) and increased expression of proliferating cell nuclear antigen (PCNA) (Maruo et al., 2000). Using an in vivo mouse model of leiomyoma, it was shown that progesterone stimulates tumor cell proliferation, accumulation of extracellular matrix, and cell hypertrophy (Ishikawa et al., 2010). However, the precise molecular mechanisms tied to progesterone have not been elucidated in full. According to our data, progesterone significantly decreases PTEN and PPARY mRNAs expression in uterine leiomyoma cell cultures in a dose-dependent fashion. Additionally, we identified a stimulatory effect of progesterone in low concentrations on PR-A and PR-B mRNAs expression by primary cell cultures.

PPARY or peroxisome proliferator-activated receptor $Y$ belongs to the nuclear hormone receptor super family and is involved in the regulation of lipid metabolism, cell proliferation, tumor growth and inflammation (Yun et al., 2018). It was shown that PPARy is expressed in different malignant tissues such as bladder, colon, prostate and breast cancer (Yun et al., 2018). Once activated by its natural (polyunsaturated fatty acids, oxidized low density lipoproteins, eicosanoids and prostaglandin metabolites) and synthetic ligands (members of antidiabetic thiazolidinedione class of drugs, including rosiglitazone, pioglitazone, ciglitizone and troglitazone), PPARy inhibits cell proliferation and induces apoptosis by up-regulating PTEN, Bax, inhibitors of cyclin-dependent kinase expression and down-regulating $X$-linked inhibitor of apoptosis, $\mathrm{Bcl}-2$, COX-2 and NF-KB (Yun et al., 2018). The literature shows that different synthetic PPARY agonists act as tumor suppressors in many types of malignant tissues (Yun et al., 2018). The role of PPARY in the pathogenesis of uterine leiomyomas is not fully understood. Jeong et al. (2010) reported higher PPARy expression in uterine leiomyoma tissue compared to the myometrium. The PPARy synthetic ligand ciglitizone reduced the survival of leiomyoma cells due to the activation of the Fas-mediated apoptosis signaling cascade (Nam et al., 2007). The molecular mecha- 

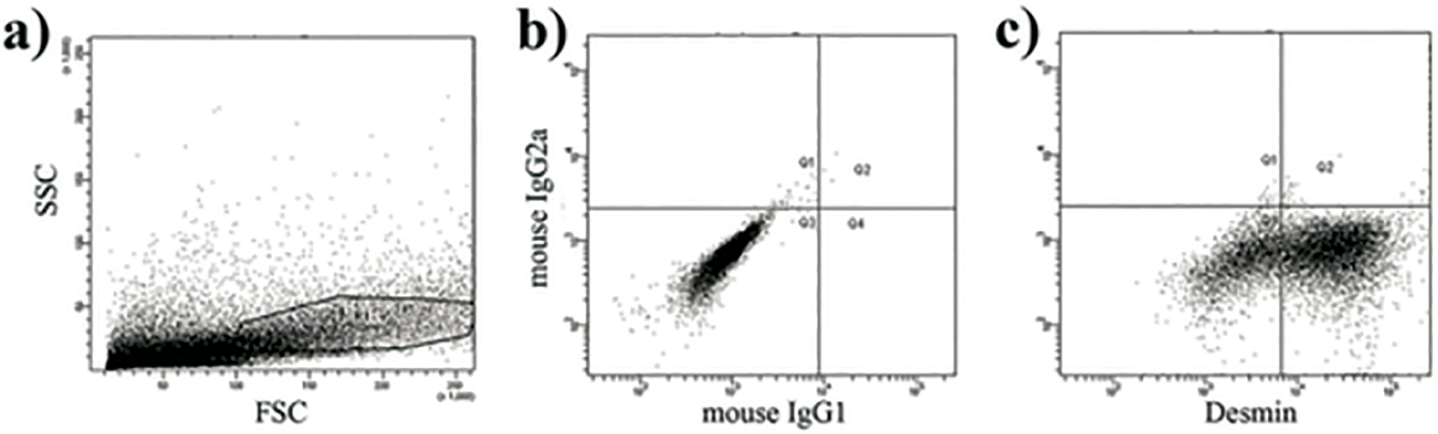

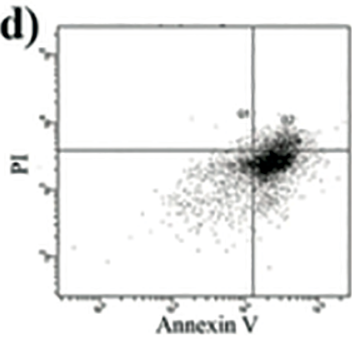

control

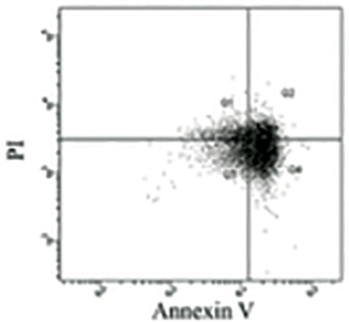

P4 $0.01 \mu \mathrm{g} / \mathrm{ml}$

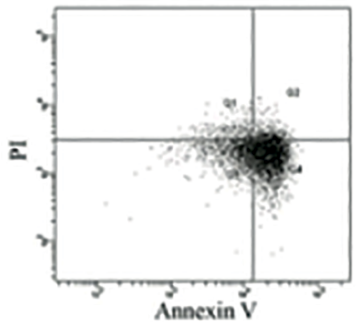

P4 $0.1 \mu \mathrm{g} / \mathrm{ml}$

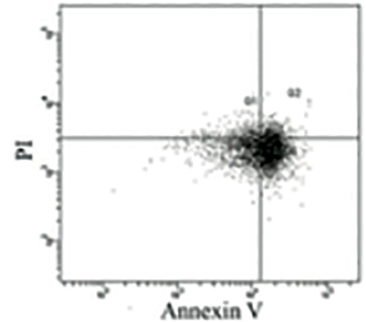

P4 $1 \mu \mathrm{g} / \mathrm{ml}$

e)

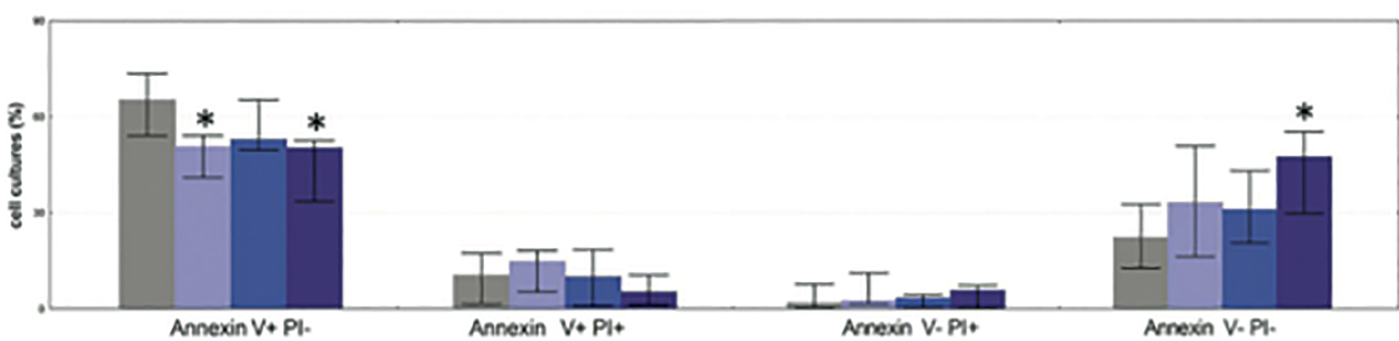

control

P4 $0.01 \mu \mathrm{g} / \mathrm{ml}$

P4 $0.1 \mu \mathrm{g} / \mathrm{ml}$

P4 $1 \mu \mathrm{g} / \mathrm{ml}$

Figure 2. Effect of progesterone treatment on the apoptosis of primary leiomyoma cells Dot plot pictures of flow cytometry assessment of leiomyoma cell apoptosis (a-d). Gate was built on the FSC (forward light scatter) vs. SSC (side light scatter) dot plot (a) to analyze cells with predominantly smooth muscle features, confirmed with desmin staining (c). The cells were stained with anti-mouse IgG1-FITC and IgG2aPE antibodies (negative control) to dicern positive from negative cells (b). Representative dot plot picture of flow cytometry data from Annexin test is shown at various progesterone (P4) concentrations $(0.01 \mu \mathrm{g} /$ $\mathrm{ml}, 0.1 \mu \mathrm{g} / \mathrm{ml}$ and $1 \mu \mathrm{g} / \mathrm{ml}$ ) (d) Effect of different concentrations of progesterone $(0.01 \mu \mathrm{g} / \mathrm{ml}, 0.1 \mu \mathrm{g} / \mathrm{ml}$ and $1 \mu \mathrm{g} / \mathrm{ml}$ ) on the relative content of early apoptotic (Annexn+PI-), late apoptotic (AnnexinV+Pi+) dead (Annexin $\mathrm{V}-\mathrm{Pi}+$ ) and viable (Annexin $\mathrm{V}-\mathrm{Pi}-$ ) leiomyoma cells (e). Error bars represent means \pm SEM. $* p<0.05$, two-tailed Student's t test with controls.

nisms of PPARy action in uterine leiomyoma tissue remains elusive, but some authors suggested that the inhibitory effects of PPARY were mediated by the interaction between estrogen receptors and PPARy signaling pathways (Houston et al., 2003). This study demonstrated that uterine leiomyoma cells have decreased PPARY mRNA expression, thus revealing a potential inhibitory effect tied to progesterone. The dose-dependent diminishment of PPARY mRNA expression after exposure of uterine leiomyoma cells to progesterone occurred concomitantly with increased cell proliferation and growth. The initially very high level of PPARY synthesis in uterine leiomyoma cells incubated only in culture medium confirms the role of this factor in the pathogenesis of leiomyoma.

PPARY up-regulates the expression of PTEN (Jeong et al., 2010). PTEN is a dual-specificity phosphatase, which is capable of removing phosphates from PI3K (phosphatidylinositol 3-kinase), thereby inhibiting the activation of the PI3K/Akt (protein kinase B) signaling pathway. This pathway plays an important role in the regulation of cell metabolism, survival, proliferation, apoptosis, growth and migration. Thus, PTEN exerts tumor suppressive functions (Keniry \& Parsons, 2008). It has been reported that PTEN mRNA expression was significantly increased in uterine leiomyoma tissue comparing to adjacent normal myometrium (Makker et al., 2016). Increased PTEN activity in uterine leiomyomas might prevent the hyperactivation of the Akt pathway and produce benign tumor growth. We found a significant dose-dependent inhibition of PTEN mRNA expression in uterine leiomyoma culture cells after exposure to progesterone. Apparently, progesterone-induced decreases in PTEN activity may be 
a)
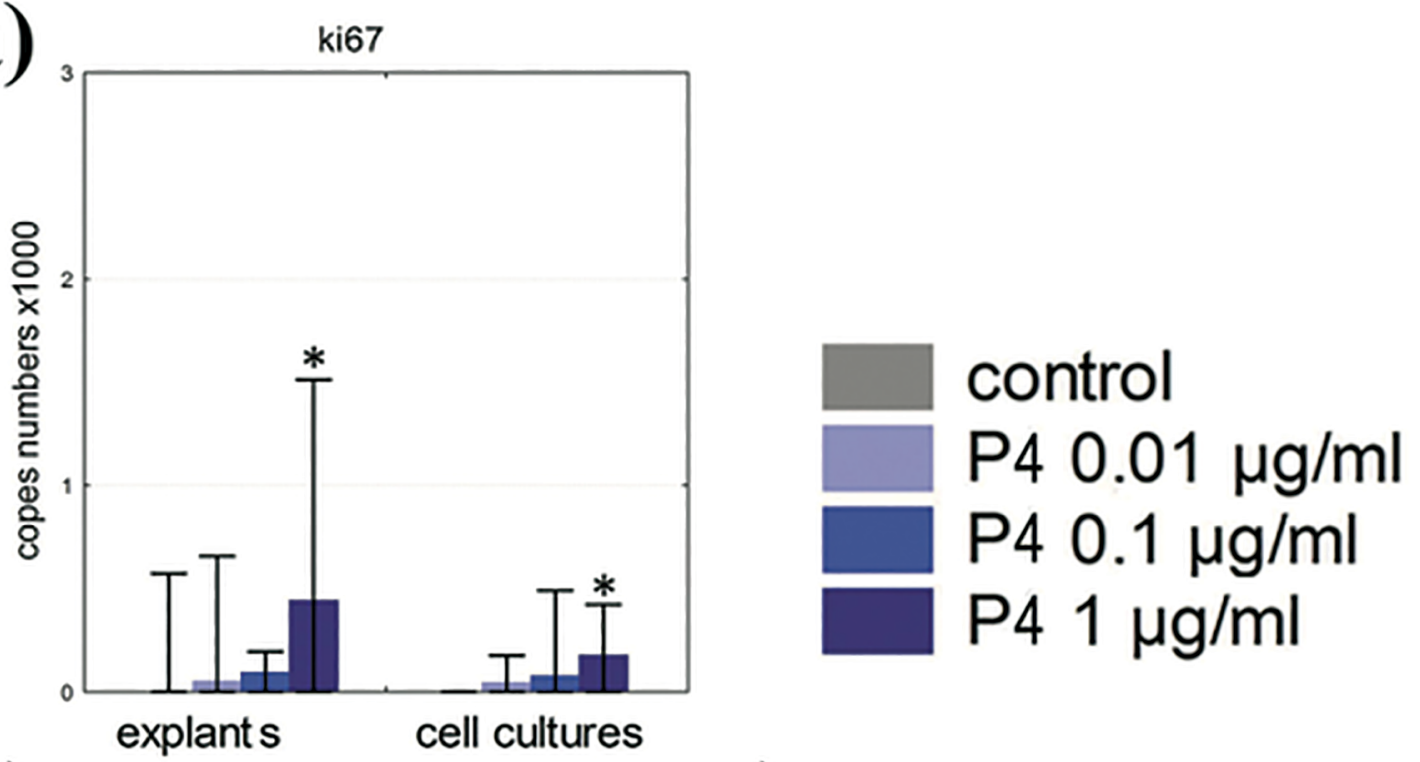

b)
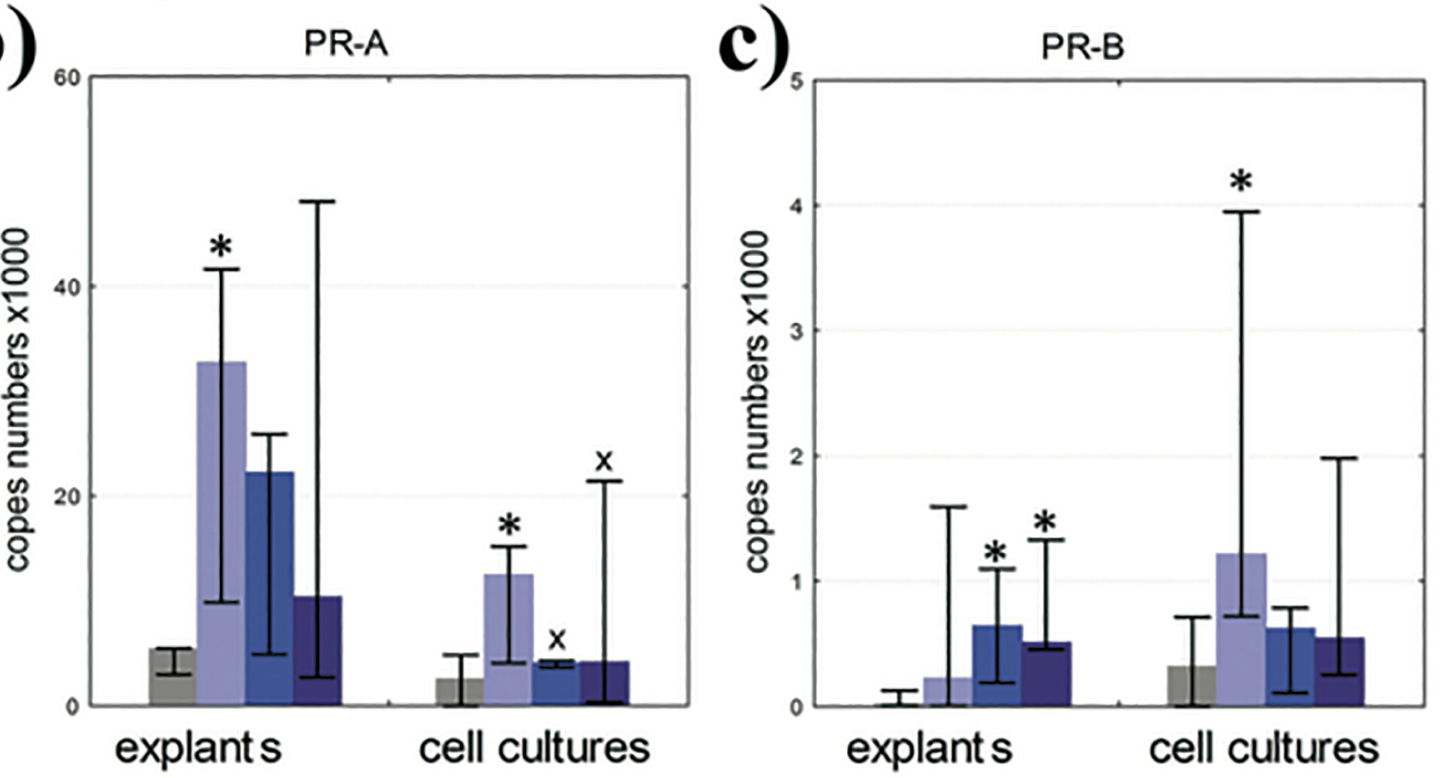

Figure 3. Comparative characteristic of PR-A, PR-B and Ki67 mRNAs expression in leiomyoma tissue explants and leiomyoma primary cultures cells, incubated at different progesterone concentrations (P4) Real-time PCR shows the effect of progesterone on Ki67 (a), PR-A (b) PR-B (c) mRNAs expression in leiomyoma tissue explants and leiomyoma primary cultures cells. Results are presented as median, first quartiles, third quartiles. *- $p<0.05$, Mann-Whitney U-test with controls, $\mathrm{x}-p<0.05$, Mann-Whitney U-test with explants.

associated with uterine leiomyoma cells proliferation and growth. However, we did not observe significant changes in Akt mRNA expression by leiomyoma cells treated with progesterone. It is well known that PTEN activity is mediated through interactions with components of the Akt-signaling pathway; one might suppose, therefore, that decreased PTEN synthesis might lead to Akt up-regulation. On the one hand, the level of Akt mRNA expression in leiomyoma cells in our experiments was consistently high and significantly exceeded that of tissue explants. Thus, decreased PTEN activity in uterine leiomyoma cultures after treatment with progesterone and stable levels of Akt activation may shift the balance of cell apoptosis and proliferation towards increased cell survival and growth. On the other hand, the absence of changes in Akt mRNA expression in leiomyoma culture cells after incubation with progesterone may be explained by specific cell culture conditions.

Primary cultures of uterine leiomyoma cells have been widely used in the investigation of fundamental biological mechanisms tied to the mediation of leiomyoma development and growth, and many authors have described the differences between cell cultures and leiomyoma tissue (Serna et al., 2018). The relevance of the in vitro leiomyoma model to native tumor tissue was studied by Bonazza et al. (2016). The authors described a classical, well-established procedure for the isolation and cultivation of uterine leiomyoma cells and reported on the expression of smooth muscle and myoblast markers and response to steroid hormones. But this in vitro leiomyoma model had several limitations such as having a limited life span, slow proliferation, and genetic diversities (Bonazza et al., 


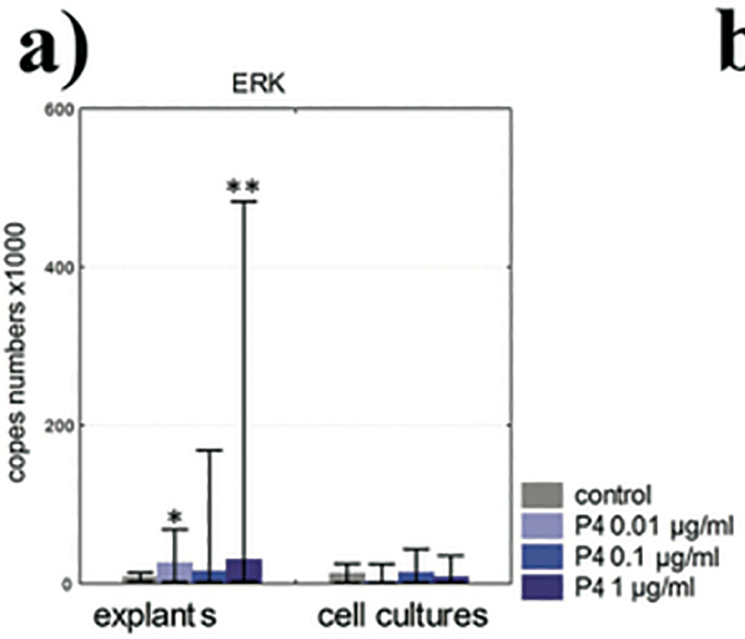

b)
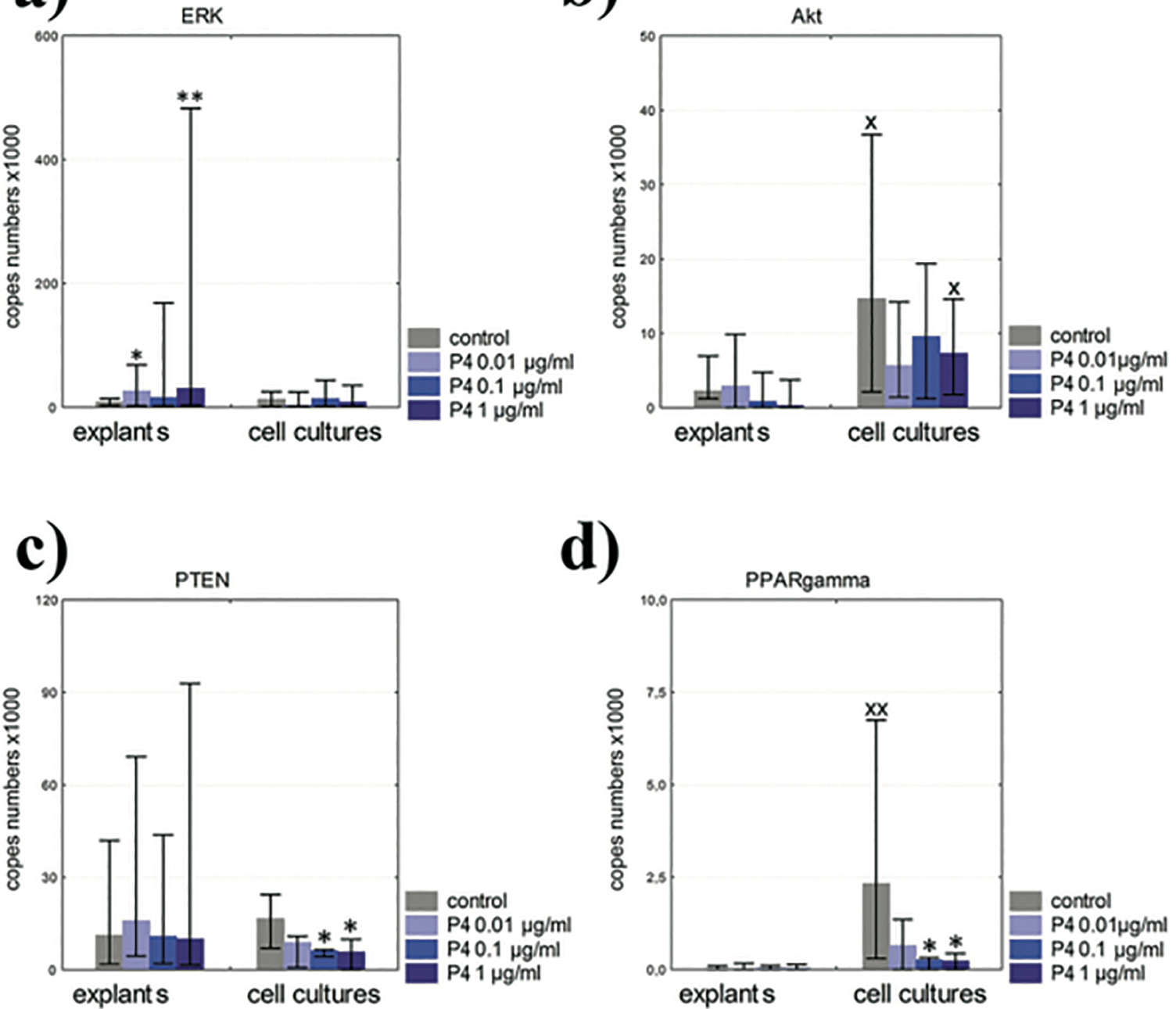

d)

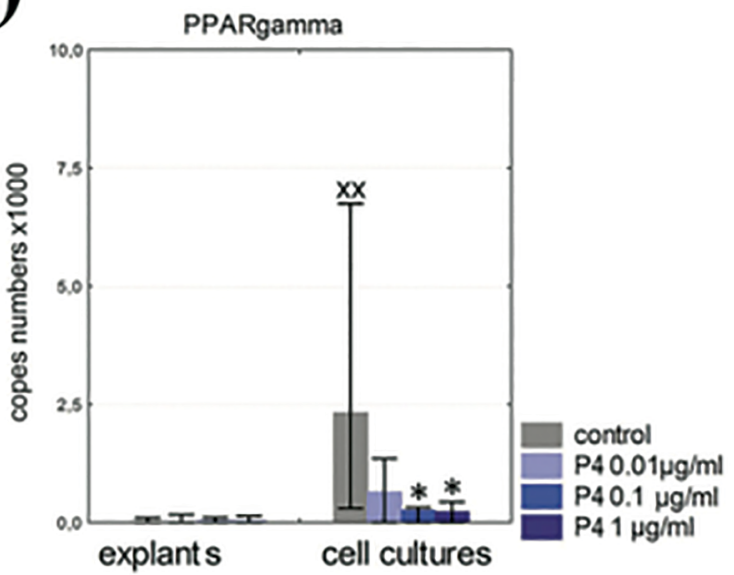

Figure 4. Comparative characteristic of ERK, AKT, PTEN and PPARY mRNAs expression in leiomyoma tissue explants and leiomyoma primary cultures cells, incubated at different progesterone concentrations (P4) Real-time PCR shows the effect of progesterone on ERK (a), AKT (b) PTEN (c) and PPARY (d) mRNAs expression in leiomyoma tissue explants and leiomyoma primary cultures cells. Results are presented as median, first quartiles, third quartiles. *- $p<0.05, * *-p<0.01$, Mann-Whitney U-test with controls, $x-$ $p<0.05, \mathrm{xx}-p<0.01$, Mann-Whitney U-test with explants.

2016). In another study, significant alterations of gene expression profiles between native tumor tissue and isolated fibroid cells were also described (Zaitseva et al., 2006). It was demonstrated that cultivation of uterine leiomyoma cells reduced the difference between model and normal myometrial cells and decreased the expression of specific estrogen and progesterone receptors mRNAs (Zaitseva et al., 2006). Our results stressed the similarities and differences in the response of leiomyoma culture cells and tissue explants to progesterone stimulation. Similar to cell cultures, high doses of progesterone induced increased expression of Ki67 mRNA, while low doses of progesterone increased PR-A mRNA expression in leiomyoma tissue explants. Unlike cell cultures, the exposure of leiomyoma tissue explants to high concentrations of progesterone produced increased PR-B mRNA expression. PR-A synthesis in tissue explants was significantly higher in these conditions than in cell cultures. Our results were consistent with published data suggesting decreased progesterone receptor expression in uterine leiomyoma cell cultures (Zaitseva et al., 2006). Progesterone stimulated cell proliferation in cell cultures and tissue explants alike, but in the case of uterine leiomyoma explants this stimulatory effect was obviously mediated by PR-B.

Unlike cell cultures, leiomyoma tissue explants treated with progesterone did not show alterations in PPARY or PTEN mRNAs expression and had increased ERK MRNA expression after exposure to low and high concentrations of progesterone. It has been demonstrated that progesterone acting via its receptors may increase the activity of the MAPK/ERK signaling pathway in cells (Ishikawa et al., 2010). The mitogen-activated protein kinase (MAPK) signaling pathway plays a key role in human cancer cell survival, migration and resistance to drug therapy (Burotto et al., 2014). MAP kinases are serine/threonine- specific protein kinases that include four signaling families: MAPK/ ERK classical pathway, Big MAK kinase-1, c-Jun N-terminal kinase and h38 signaling families (Burotto et al., 2014). The MAPK/ERK (extracellular signal regulated kinases) pathway is activated by numerous signals, such as internal metabolic stress, DNA damage, altered protein concentrations, in addition to signaling from growth factors, cell-matrix and cell-cell interactions (Yang et al., 2013). Engagement of the ERK pathway activates the AP-1 (activating 
protein-1) family of transcription factors, which modulates the transcription of several target genes regulating proliferation and invasion (Borahay et al., 2015). Recent investigations have demonstrated the complex and bidirectional interaction between steroid hormones and the ERK-signaling pathway (Borahay et al., 2015). On the one hand, estrogens and progesterone may directly activate the ERK pathway; on the other hand, growth factors can modulate ERK response to steroids, thus targeting steroid receptors (Lopez et al., 2001). We suppose that the increased ERK mRNA expression seen in uterine leiomyoma tissue explants after incubation with progesterone may be induced by the direct action of progesterone and by the specific tumor microenvironment. It is well known that numerous growth factors and proinflammatory cytokines, including TGF (transforming growth factor), EGF (epidermal growth factor), IL (interleukin) -1 and -8 , TNFa (tumor necrosis factor a) and others, are synthesized in the uterine leiomyoma tissue and play an important role in the mechanisms of leiomyoma growth (Chegini, 2010). The stimulatory effect of IL-8, TNFa and TGF 33 upon the ERK pathway has also been demonstrated (Chan et al., 2017; Wolczyk et al., 2016; Tao et al., 2015). It might be inferred that the specific leiomyoma tissue microenvironment, characterized by increased expression of a variety of growth factors and proinflammatory cytokines, might interfere with progesterone and promote the proliferation of uterine leiomyoma cells by activating the MAPK/ERK pathway via PR-B receptors as well. Our results allow us to speculate about the differences in the stimulatory action of progesterone on leiomyoma cell cultures and whole tissue explants and their potential associations with the specific cytokine microenvironment in tissue explants.

\section{CONCLUSION}

This study described a direct dose-dependent inhibitory effect of progesterone on the apoptosis of primary uterine leiomyoma cell cultures. This finding was associated with elevated Ki67 mRNA expression in tumor cells and enhanced cell growth in response to high doses of progesterone. This effect may be mediated through the effects of progesterone on PTEN and PPARy synthesis in leiomyoma cells. Low doses of progesterone increased PR-A and PR-B mRNAs expression in tumor cells. High doses of progesterone increased $\mathrm{Ki} 67$ and PR-A mRNAs expression. In tissue explants, a dose-dependent effect of progesterone on PR-B mRNA expression and a stimulatory effect of low and high doses of progesterone on ERK activity were observed. Therefore, progesterone acts quite differently in uterine leiomyoma cell cultures and tissue explants, a factor that must be taken into the account in the development of pharmacological strategies to regulate progesterone activity in uterine leiomyomas.

\section{ACKNOWLEDGEMENTS}

This study was funded by grant № 15-04-05042 from the Russian Fund for Fundamental Research.

\section{Author Contributions}

Y.S. contributed in conception and design. D.V. contributed in all stages of experimental work, N.S. contributed in data analysis and interpretation. A.M. was responsible for overall supervision and consultation. S.N. contributed in data collection. All authors read and approved the final manuscript.

\section{CONFLICT OF INTEREST}

The authors have no conflict of interest to declare.

\section{Corresponding author:}

Natalia Sotnikova

Federal State Budget Institute "Ivanovo's

Research Institute of the Maternity and Childhood named V.N.Gorodkov" of the Health Ministry of Russia Ivanovo, Russia

E-mail: niimid.immune@mail.ru

\section{REFERENCES}

Bonazza C, Andrade SS, Sumikawa JT, Batista FP, Paredes-Gamero EJ, Girão MJ, Oliva ML, Castro RA. Primary Human Uterine Leiomyoma Cell Culture Quality Control: Some Properties of Myometrial Cells Cultured under Serum Deprivation Conditions in the Presence of Ovarian Steroids. PLoS One. 2016;11:e0158578. PMID: 27391384 DOI: $10.1371 /$ journal. pone.0158578

Borahay MA, Al-Hendy A, Kilic GS, Boehning D. Signaling Pathways in Leiomyoma: Understanding Pathobiology and Implications for Therapy. Mol Med. 2015;21:242-56. PMID: 25879625 DOI: 10.2119/molmed.2014.00053

Burotto M, Chiou VL, Lee JM, Kohn EC. The MAPK pathway across different malignancies: a new perspective. Cancer. 2014;120:3446-56. PMID: 24948110 DOI: 10.1002/ cncr. 28864

Chan LP, Liu C, Chiang FY, Wang LF, Lee KW, Chen WT, Kuo $\mathrm{PL}$, Liang $\mathrm{CH}$. IL-8 promotes inflammatory mediators and stimulates activation of $\mathrm{p} 38 \mathrm{MAPK} / \mathrm{ERK}-\mathrm{NF}-\mathrm{KB}$ pathway and reduction of JNK in HNSCC. Oncotarget. 2017;8:5637588. PMID: 28915597 DOI: 10.18632/oncotarget. 16914

Chegini N. Proinflammatory and profibrotic mediators: principal effectors of leiomyoma development as a fibrotic disorder. Semin Reprod Med. 2010;28:180-203. PMID: 20414842 DOI: $10.1055 / \mathrm{s}-0030-1251476$

Commandeur AE, Styer AK, Teixeira JM. Epidemiological and genetic clues for molecular mechanisms involved in uterine leiomyoma development and growth. Hum Reprod Update. 2015;21:593-615. PMID: 26141720 DOI: 10.1093 /humupd/dmv030

Havryliuk Y, Setton R, Carlow JJ, Shaktman BD. Symptomatic Fibroid Management: Systematic Review of the Literature. JSLS. 2017;21:e2017.00041. PMID: 28951653 DOI: 10.4293/JSLS.2017.00041

Hennessy BT, Smith DL, Ram PT, Lu Y, Mills GB. Exploiting the PI3K/AKT pathway for cancer drug discovery. Nat Rev Drug Discov. 2005;4:988-1004. PMID: 16341064 DOI: $10.1038 / \mathrm{nrd} 1902$

Hoekstra AV, Sefton EC, Berry E, Lu Z, Hardt J, Marsh E, Yin P, Clardy J, Chakravarti D, Bulun S, Kim JJ. Progestins activate the AKT pathway in leiomyoma cells and promote survival. J Clin Endocrinol Metab. 2009;94:1768-74. PMID: 19240153 DOI: $10.1210 / j c .2008-2093$

Houston KD, Copland JA, Broaddus RR, Gottardis MM, Fischer SM, Walker CL. Inhibition of proliferation and estrogen receptor signaling by peroxisome proliferator-activated receptor gamma ligands in uterine leiomyoma. Cancer Res. 2003;63:1221-7. PMID: 12649180 
Ishikawa H, Ishi K, Serna VA, Kakazu R, Bulun SE, Kurita $\mathrm{T}$. Progesterone is essential for maintenance and growth of uterine leiomyoma. Endocrinology. 2010;151:2433-42. PMID: 20375184 DOI: 10.1210/en.2009-1225

Jeong YJ, Noh EM, Lee YR, Yu HN, Jang KY, Lee SJ, Kim J, Kim JS. 17beta-estradiol induces up-regulation of PTEN and PPARgamma in leiomyoma cells, but not in normal cells. Int J Oncol. 2010;36:921-7. PMID: 20198337 DOI: 10.3892/ijo_00000571

Kasai T, Shozu M, Murakami K, Segawa T, Shinohara K, Nomura K, Inoue M. Increased expression of type I 17beta-hydroxysteroid dehydrogenase enhances in situ production of estradiol in uterine leiomyoma. J Clin Endocrinol Metab. 2004;89:5661-8. PMID: 15531526 DOI: 10.1210/ jc. 2003-032085

Keniry M, Parsons R. The role of PTEN signaling perturbations in cancer and in targeted therapy. Oncogene. 2008;27:5477-85. PMID: 18794882 DOI: 10.1038/ onc. 2008.248

Kim JJ, Sefton EC, Bulun SE. Progesterone receptor action in leiomyoma and endometrial cancer. Prog Mol Biol Transl Sci. 2009;87:53-85. PMID: 20374701 DOI: 10.1016/ S1877-1173(09)87002-6

Koohestani F, Braundmeier AG, Mahdian A, Seo J, Bi J, Nowak RA. Extracellular matrix collagen alters cell proliferation and cell cycle progression of human uterine leiomyoma smooth muscle cells. PLoS One. 2013;8:e75844. PMID: 24040420 DOI: $10.1371 /$ journal.pone.0075844

Lange CA. Integration of progesterone receptor action with rapid signaling events in breast cancer models. J Steroid Biochem Mol Biol. 2008;108:203-12. PMID: 17964138 DOI: https://doi.org/10.1016/j.jsbmb.2007.09.019

Lopez GN, Turck CW, Schaufele F, Stallcup MR, Kushner PJ. Growth factors signal to steroid receptors through mitogen-activated protein kinase regulation of p160 coactivator activity. J Biol Chem. 2001;276:22177-82. PMID: 11301320 DOI: $10.1074 /$ jbc.M010718200

Makker A, Goel MM, Mahdi AA, Bhatia V, Das V, Agarwal A, Pandey A. PI3K/Akt/mTOR signaling \& its regulator tumour suppressor genes PTEN \& LKB1 in human uterine leiomyomas. Indian J Med Res. 2016;143:S112-9. PMID: 27748285 DOI: $10.4103 / 0971-5916.191808$

Maruo $T$, Matsuo $H$, Samoto $T$, Shimomura $Y$, Kurachi $O$, Gao Z, Wang Y, Spitz IM, Johansson E. Effects of progesterone on uterine leiomyoma growth and apoptosis. Steroids. 2000;65:585-92. PMID: 11108863 DOI: 10.1016/ S0039-128X(00)00171-9
Mas A, Nair S, Laknaur A, Simón C, Diamond MP, Al-Hendy A. Stro-1/CD44 as putative human myometrial and fibroid stem cell markers. Fertil Steril. 2015;104:225-34.e3. PMID: 25989979 DOI: 10.1016/j.fertnstert.2015.04.021

Nam DH, Ramachandran S, Song DK, Kwon KY, Jeon DS, Shin SJ, Kwon SH, Cha SD, Bae I, Cho CH. Growth inhibition and apoptosis induced in human leiomyoma cells by treatment with the PPAR gamma ligand ciglitizone. Mol Hum Reprod. 2007;13:829-36. PMID: 17893092 DOI: 10.1093/molehr/gam071

Reis FM, Bloise E, Ortiga-Carvalho TM. Hormones and pathogenesis of uterine fibroids. Best Pract Res Clin Obstet Gynaecol. 2016;34:13-24. PMID: 26725037 DOI: 10.1016/j.bpobgyn.2015.11.015

Serna VA, Wu X, Qiang W, Thomas J, Blumenfeld ML, Kurita T. Cellular kinetics of MED12-mutant uterine leiomyoma growth and regression in vivo. Endocr Relat Cancer. 2018;25:747-59. PMID: 29700012 DOI: 10.1530/ERC-18-0184

Tao Y, Zhou X, Liang C, Li H, Han B, Li F, Chen Q. TGF- $\beta 3$ and IGF-1 synergy ameliorates nucleus pulposus mesenchymal stem cell differentiation towards the nucleus pulposus cell type through MAPK/ERK signaling. Growth Factors. 2015;33:326-36. PMID: 26431359 DOI: $10.3109 / 08977194.2015 .1088532$

Wolczyk D, Zaremba-Czogalla M, Hryniewicz-Jankowska A, Tabola R, Grabowski K, Sikorski AF, Augoff K. TNF-a promotes breast cancer cell migration and enhances the concentration of membrane-associated proteases in lipid rafts. Cell Oncol (Dordr). 2016;39:353-63. PMID: 27042827 DOI: $10.1007 / \mathrm{s} 13402-016-0280-x$

Yang SH, Sharrocks AD, Whitmarsh AJ. MAP kinase signalling cascades and transcriptional regulation. Gene. 2013;513:113. PMID: 23123731 DOI: 10.1016/j.gene.2012.10.033

Yin $\mathrm{P}$, Lin Z, Cheng $\mathrm{YH}$, Marsh EE, Utsunomiya $\mathrm{H}$, Ishikawa $\mathrm{H}$, Xue Q, Reierstad S, Innes J, Thung S, Kim JJ, Xu E, Bulun $\mathrm{SE}$. Progesterone receptor regulates $\mathrm{Bcl}-2$ gene expression through direct binding to its promoter region in uterine leiomyoma cells. J Clin Endocrinol Metab. 2007;92:445966. PMID: 17785366 DOI: 10.1210/jc.2007-0725

Yun SH, Han SH, Park JI. Peroxisome Proliferator-Activated Receptor $Y$ and PGC-1a in Cancer: Dual Actions as Tumor Promoter and Suppressor. PPAR Res. 2018;2018:6727421. PMID: 29599799 DOI: $10.1155 / 2018 / 6727421$

Zaitseva M, Vollenhoven BJ, Rogers PA. In vitro culture significantly alters gene expression profiles and reduces differences between myometrial and fibroid smooth muscle cells. Mol Hum Reprod. 2006;12:187-207. PMID: 16524927 DOI: $10.1093 / \mathrm{molehr} / \mathrm{gal} 018$ 